\title{
Identification of androgen receptor phosphorylation in the primate ovary in vivo
}

\author{
Iain J McEwan ${ }^{1,2}$, Dagmara McGuinness ${ }^{1}$, Colin W Hay ${ }^{2}$, Robert P Millar $^{1}$, Philippa T K Saunders ${ }^{1}$ \\ and Hamish M Fraser ${ }^{1}$ \\ ${ }^{1}$ MRC Human Reproductive Sciences Unit, Queen's Medical Research Institute, 47 Little France Crescent, Edinburgh \\ EH16 4TJ, Scotland, UK and ${ }^{2}$ School of Medical Sciences, University of Aberdeen, Foresterhill, Aberdeen AB25 2ZD, \\ Scotland, UK
}

Correspondence should be addressed to I J McEwan at School of Medical Sciences, University of Aberdeen; Email: iain.mcewan@abdn.ac.uk

\begin{abstract}
The androgen receptor (AR) is a member of the nuclear receptor superfamily, and is important for both male and female reproductive health. The receptor is a target for a number of post-translational modifications including phosphorylation, which has been intensively studied in vitro. However, little is known about the phosphorylation status of the receptor in target tissues in vivo. The common marmoset is a useful model for studying human reproductive functions, and comparison of the AR primary sequence from this primate shows high conservation of serines known to be phosphorylated in the human receptor and corresponding flanking amino acids. We have used a panel of phosphospecific antibodies to study AR phosphorylation in the marmoset ovary throughout the follicular phase and after treatment with GNRH antagonist or testosterone propionate. In normal follicular phase ovaries, total AR (both phosphorylated and non-phosphorylated forms) immunopositive staining was observed in several cell types including granulosa cells of developing follicles, theca cells and endothelial cells lining blood vessels. Receptor phosphorylation at serines 81, 308, and 650 was detected primarily in the granulosa cells of developing follicles, surface epithelium, and vessel endothelial cells. Testosterone treatment lead to a modest increase in AR staining in all stages of follicle studied, while GNRH antagonist had no effect. Neither treatment significantly altered the pattern of phosphorylation compared to the control group. These results demonstrate that phosphorylation of the AR occurs, at a subset of serine residues, in a reproductive target tissue in vivo, which appears refractory to hormonal manipulations.

Reproduction (2010) 140 93-104
\end{abstract}

\section{Introduction}

The androgen receptor (AR) is a member of the nuclear receptor superfamily and mediates the action of the sex steroids testosterone and dihydrotestosterone (Gelmann 2002, McEwan 2004). The AR is expressed in reproductive tissues of both males and females, and is known to play important roles in fertility. However, regulation of AR function and the identity of target genes for the receptor in different tissues are less well understood.

Folliculogenesis involves the formation of a multi-cell layer of granulosa cells surrounding the oocyte, which in turn are surrounded by a theca cell layer. The theca cells are responsible for the biosynthesis of androgens, which can be converted to estrogens by the aromatase enzyme that is expressed in granulosa cells in response to FSH stimulation (Fauser \& Van Heusden 1997, Hillier 2001, Jamnongjit \& Hammes 2006). Androgenic steroids play important roles in follicle growth and survival as precursors for estrogen biosynthesis and directly through binding to and activation of the AR. The AR has been shown to induce expression of the genes for insulin-like growth factor 1 (IGF1), IGF1 receptor, and FSH receptor, and to augment growth differentiation factor 9 and FSH signaling in granulosa cells (Weil et al. 1999, Hickey et al. 2005, Walters et al. 2007, Lenie \& Smitz 2009). Expression of both mRNA and protein for the AR in granulosa cells of the developing follicles has been described in the ovaries from both human (Horie et al. 1992, Chadha et al. 1994, Rice et al. 2007) and a number of non-human primates including rhesus monkey (Weil et al. 1998, Chaffin et al. 1999), baboon (Hild-Petito \& Fazleabas 1997), and the common marmoset, Callithrix jacchus (Hillier et al. 1997, Saunders et al. 2000). AR expression has also been observed and studied in ovaries from mouse (Kimura et al. 2007), rat (Tetsuka et al. 1995, Tetsuka \& Hillier 1996), and sheep (Juengel et al. 2006). In these diverse 
studies, the consensus findings are that AR protein levels change during follicle development, with the highest levels seen in primary to tertiary stage follicles. Significantly, three complete AR knockout (ARKO) mouse models resulted in reduced fertility in female animals due to defects in folliculogenesis (Yeh et al. 2002, Hu et al. 2004, Shiina et al. 2006, Walters et al. 2007).

The $A R$ is subject to a range of post-translational modifications, including phosphorylation on serine (van Laar et al. 1991, Gioeli et al. 2002, Lin et al. 2002, Ponguta et al. 2008) and tyrosine (Mahajan et al. 2007) residues, and acetylation (Fu et al. 2002, Gaughan et al. 2002), and sumoylation (Poukka et al. 2000, Callewaert et al. 2004) on lysine residues. Up to 11 phosphorylated serine and 1 tyrosine residues have been identified to date in cell culture systems after different hormonal or growth factor stimulations (van Laar et al. 1991, Gioeli et al. 2002, Lin et al. 2002, Mahajan et al. 2007, Ponguta et al. 2008). Phosphorylation of the receptor protein represents a potentially powerful means of regulating receptor levels and function, without the requirement for de novo synthesis. However, little is known about the phosphorylation status of the AR in normal target tissues in vivo. Recently, a number of phosphoserine-specific antibodies have been described for the AR (Black et al. 2004, Taneja et al. 2005, Yang et al. 2005, Ponguta et al. 2008), and the availability of these tools provides the possibility of screening archival tissue samples for cell-specific or developmental changes in receptor phosphorylation, which will be important for a fuller understanding of the role of this chemical modification.

Of the commonly used non-human primate models in reproduction research, the marmoset, $C$. jacchus, has particular advantages with respect to the study of ovarian folliculogenesis. First, marmosets normally ovulate three follicles per cycle (range 1-4) that reach up to $4 \mathrm{~mm}$ in diameter so that during the mid-late follicular phase, the ovaries contain a wealth of follicles at different stages of development (Gilchrist et al. 2001). Also, the presence of follicular tissue is emphasized because prostaglandininduced structural luteolysis leads to removal of luteal tissue. Marmoset ovaries, weighing around $150 \mathrm{mg}$, are ideal to study, being easily accommodated on a microscope slide, so that in ovaries of the mid- and late follicular phase, numerous follicles at different stages of development can be compared within each section. Furthermore, in our laboratory, a number of studies have been performed in which follicular development has been influenced by inhibition of GNRH (Taylor et al. 2004, 2007), allowing the secondary effects of this treatment to be investigated (Thomas et al. 2007). In the present study, we have addressed the question of changes in and regulation of AR phosphorylation at different stages of development in the marmoset ovary at the normal follicular phase and after manipulation of testosterone levels by suppressing ovarian sex steroid secretion by GNRH antagonist treatment or by increasing exposure to testosterone by administration of testosterone propionate in vivo as described in the rhesus macaque (Vendola et al. 1999). By employing immunohistochemical localization using a panel of three phosphoserine-specific antibodies, as well as antibodies recognizing total levels of receptor, we have investigated for the first time the phosphorylation of the $A R$ in the primate ovary.

\section{Results}

Eleven phosphorylated serine residues have been identified which are distributed throughout the length of the AR (Fig. 1A; van Laar et al. 1991, Gioeli et al. 2002, Lin et al. 2002, Ponguta et al. 2008). In order to determine whether receptor phosphorylation occurs in vivo in a target tissue, a panel of antibodies recognizing phosphorylated serines 81,308 , and 650 were used on marmoset ovarian tissue sections. The predicted marmoset AR is 887 amino acids in length and has a theoretical molecular mass of $95659 \mathrm{kDa}$. Analysis of the primary amino acid sequence for the marmoset AR revealed strong conservation of serines corresponding to residues in the human AR at positions 81, 94, 308, and 650, which are known to be phosphorylated in the human receptor (Jenster et al. 1994, Zhou et al. 1995, Blok et al. 1998, Lin et al. 2001, Zhu et al. 2001, Gioeli et al. 2002, Rigas et al. 2003, Black et al. 2004, Wong et al. 2004, Chen et al. 2006, Kesler et al. 2007, Yang et al. 2007, Zong et al. 2007, Ponguta et al. 2008; Fig. 1B). In addition, there was high conservation of flanking amino acids especially a proline at positions 82, 95, 309, and 651 immediately C-terminal of the phosphorylated serine (Fig. 1B). In contrast, the mouse and rat ARs have changes in flanking amino acids, which may impair phosphorylation or detection with phospho-specific antibodies raised against the human sequence. Indeed, none of the phospho-specific antibodies tested appeared to cross-react with the mouse or rat AR in immunohistochemistry (data not shown). Figure 1C shows a western blot of marmoset ovarian tissue extract probed with an antibody against the N-terminus (N20) of the receptor that recognizes both phosphorylated and non-phosphorylated forms of the receptor. The marmoset AR migrated a little slower than the $98 \mathrm{kDa}$ marker. After immunoprecipitation (IP) of the $A R$, with an antibody against the C-terminal domain (C19), but not a control IgG, forms of the receptor phosphorylated on serines 81, 308, and 650 were detected (Fig. 1D), indicating post-translational modification of the receptor in the primate ovary.

Morphological description of control and GNRH antagonist-treated ovaries has been reported previously (Taylor et al. 2004). Briefly, all classes of developing follicles up to the stage of dominant follicles were 
A

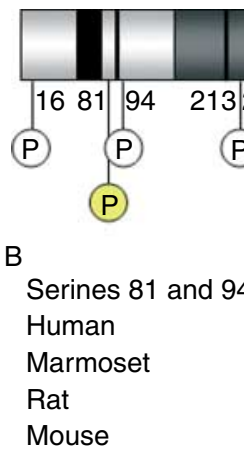

Serine 308

Human

Marmoset

Rat

Mouse

\section{LBD}

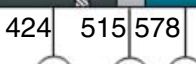

(P) (P) $P$

(P) $(P)$

(P)

$$
\sqrt{2}
$$

\section{(1)} QQQQQQQQE T SPRQ

(P)

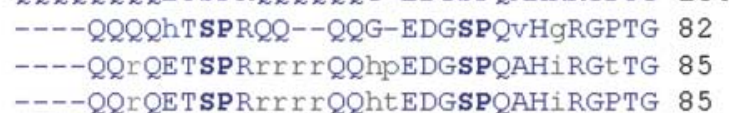

(P)

(P)

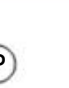

----QQrQETSPRrrrQQhtEDGSPQAHIRGPTG 85
Serine 650

Human

Marmoset

Rat

Mouse
(P)

LDDSAGKSTEDTAEYSPFKGGYTKGLE 322

LDDSAGKGTEDTAEYSPEKGGYTKVLE 300

LDegpGKGTE TAEYSSEKGGYaKGLE 317

LDegpGKsTEeTAEYSSFKGGYaKGLE 314
C

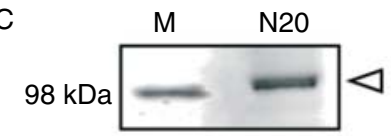

D

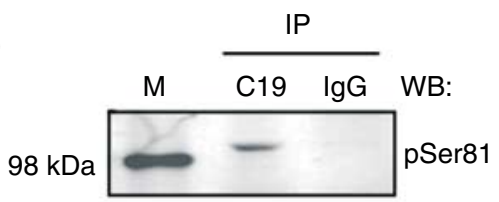

$98 \mathrm{kDa}$

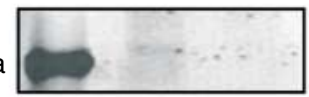

pSer308

$98 \mathrm{kDa}$

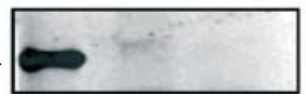

(P)

(PISTTOKLTV 661

GNLKLQEEGEnSSagSPTEdpsQKmTV 643

GNLKLQEEGEnSnagSPTEdpsQKmTV 641

Figure 1 Comparison of primary amino acid sequence of the human, marmoset, and rodent AR. (A) Schematic representation of the human androgen receptor (AR) showing the domain organization and the position of 11 phosphorylated serine residues. The residues analyzed in the present study are highlighted in yellow. LBD, ligand-binding domain; DBD, DNA-binding domain; AF1, activation function 1.

(B) Comparison of the primary amino acid sequence of the human, marmoset, rat, and mouse AR. Only partial amino acid sequence is shown for four phosphorylated serine residues $(P)$. (C) Western blot analysis of total AR (N20 antibody detecting both non-phosphorylated+ phosphorylated forms) in a protein extract of the marmoset ovary. $M$, molecular weight marker. (D) The AR was immunoprecipitated using antibody C19 (against the AR-LBD) and the membranes probed with the phospho-specific antibodies (against phosphoserines 81, 308, and 650). IgG represents a control immunoprecipitation using a non-receptor-specific antibody as a control. IP, immunoprecipitation; WB, western blot.

present in all three groups, while the latter class was present in the day 10 controls only (2-4 per animal). As anticipated, treatment with testosterone propionate was also associated with the presence of large numbers of antral follicles and the absence or reduction in numbers of dominant follicles. In order to determine the location of the phosphorylated AR in the ovary, immunohistochemistry was undertaken on whole tissue sections. Examination of ovaries at the two control stages of the cycle revealed a similar intensity of staining within each class of follicle, irrespective of stage. Because healthy tertiary follicles were most abundant in the day 5 ovaries, these were selected for semi-quantitative analysis and only pre-ovulatory follicles from the day 10 controls were scored. As reported previously (Hillier et al. 1997, Saunders et al. 2000), in the ovaries of control marmosets, AR-positive nuclear staining was observed in the granulosa cells at all stages of follicle development when sections were incubated with an antibody directed against the $\mathrm{N}$-terminus of the mature protein (Fig. 2A N20). AR-positive staining in granulosa cells increased as follicles developed (Fig. 2A panels a and $\mathrm{d}$ and $\mathrm{B}$ ), and began to decrease during early and late atresia (data not shown). The theca cell layer, stroma, 


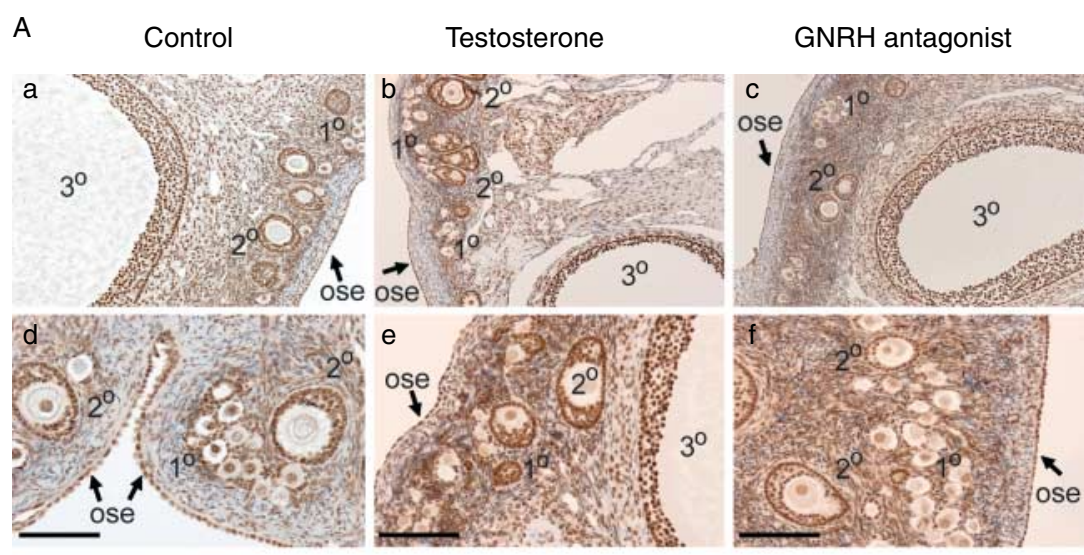

N20

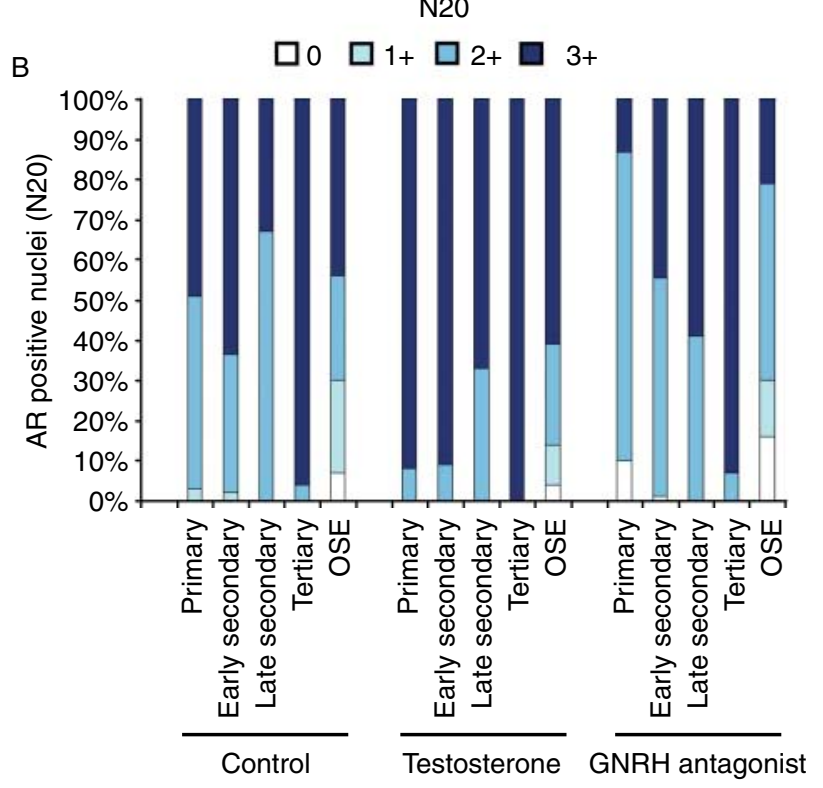

Figure $2 \mathrm{AR}$ expression in the marmoset ovary. (A) Immunohistochemistry staining for total AR using an antibody against the first 20 amino acids (N20). Panels a and d, control group; panels b and e, after treatment with testosterone propionate; and panels $\mathrm{c}$ and $\mathrm{f}$, after treatment with $\mathrm{GNRH}$ antagonist. Panels $\mathrm{a}-\mathrm{C}$ and $\mathrm{d}-\mathrm{f}$ represent $\times 10$ and $\times 20$ magnification respectively; size bar $=100 \mu \mathrm{m} .1^{\circ}, 2^{\circ}$, and $3^{\circ}$ examples of primary, secondary, and tertiary follicles are shown; OSE, ovarian surface epithelium. (B) Scoring for the relative strength of staining for total $A R$ in control animals (day 5); after treatment with GNRH antagonist on day 0; and after treatment with testosterone propionate on day 0 . Ovaries from four animals were analyzed for each condition, and scoring was done as detailed in Materials and Methods. Briefly, only primary/transitional and secondary follicles with a clearly visible oocyte were scored as follows: 0 , no detectable staining; $1+, 2+$, and $3+$, weak, moderate, and strong staining respectively. The percentage of granulosa cells at each intensity for primary, secondary, and tertiary follicles has been plotted together with the percentage of OSE. and regions of the ovarian surface epithelium (OSE) also all stained positive for AR (Fig. 2A panels a and d).

Treatment with testosterone propionate resulted in strong staining for total $A R$ in primary follicles through to tertiary follicles and the OSE (Fig. 2A panels $b$ and $e$ and B). From the semi-quantitative scoring of the AR staining, it could be seen that there was an overall increase in the levels of receptor at all stages of follicle growth, especially primary and secondary follicles (Fig. 2B).

To investigate the effect of GNRH antagonist treatment on AR phosphorylation, ovarian sections from animals treated on day 0 were stained for total $A R$ or selected phosphoserine modifications. After GNRH antagonist treatment, AR staining was observed in all stages of follicle present, and again predominantly in granulosa and theca cells of primary, secondary, and tertiary follicles and reduced in atretic follicles (Fig. 2A panels C and $f$ and $B$ ). This treatment results in failure of emergence of dominant follicles (Taylor et al. 2004).

Phosphorylated forms of the AR were similarly observed at all stages of follicle growth. The pattern of phosphorylated serine 81 essentially mirrors that of total AR with most intense immunopositive staining seen in the secondary and tertiary follicles and the OSE (Fig. 3A panel a and B). Nuclear staining was also detected in the theca cell layer.

Phosphorylation on serine 308, also present in the AR-amino terminal domain (NTD), was restricted mainly to the granulosa cells of secondary and tertiary follicles with little or no staining of primary (Fig. 4A panel a and B) or pre-ovulatory follicles (data not shown). Phosphorylation of serine 308 was also more punctate, with some strongly staining granulosa cells (Fig. 4).

The pattern of phosphorylation of serine 650, located within the hinge domain, was observed in all stages of follicle development from primary onwards, with the most intense staining seen in secondary and tertiary follicles (Fig. 5A panel a and B). Immunopositive staining was reduced, but still observable in pre-ovulatory/dominant follicles and reduced or absent in atretic follicles (data not shown).

Staining for total AR and phosphoserines 81 and 650 was also observed in regions of the OSE, while staining 
A

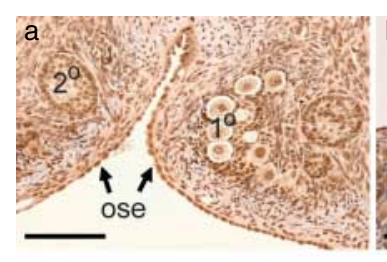

Testosterone

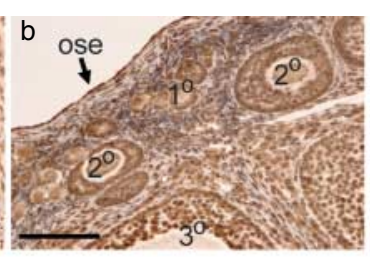

pSer81

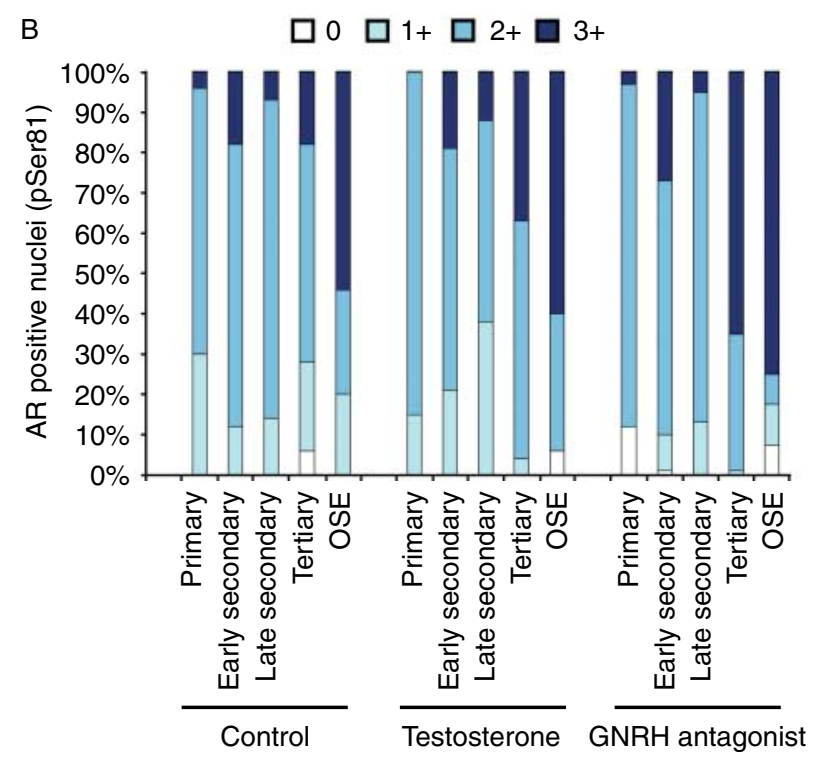

GNRH antagonist

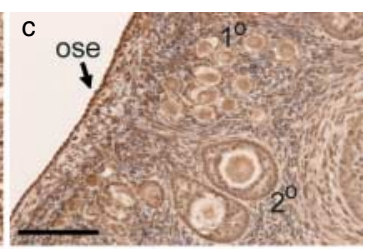

Figure 3 Detection of AR phosphorylated on serine 81 . (A) Immunohistochemistry staining for AR using an antibody against phosphoserine 81 (pSer81). Panel a, control animal (day 5); panel $b$, after treatment with testosterone propionate; and panel c, after treatment with GNRH antagonist. Panels a-c represent $\times 20$ magnification; size bar $=100 \mu \mathrm{m} .1^{\circ}, 2^{\circ}$, and $3^{\circ}$ examples of primary, secondary, and tertiary follicles are shown; OSE, ovarian surface epithelium. (B) Scoring for the relative strength of staining for total AR in control animals (day 5); after treatment with GNRH antagonist on day 0; and after treatment with testosterone propionate on day 0 . Ovaries from four animals were analyzed for each condition, and scoring was done as detailed in Materials and Methods. Briefly, only primary/transitional and secondary follicles with a clearly visible oocyte were scored as follows: 0 , no detectable staining; $1+$, $2+$, and $3+$, weak, moderate, and strong staining respectively. The percentage of granulosa cells at each intensity for primary, secondary, and tertiary follicles has been plotted together with the percentage of OSE. for phosphoserine 308 was more patchy with only some cells staining positive (Figs 2-5). It is also noteworthy that positive staining for total and phosphorylated forms of the AR was also observed in about $30 \%$ of endothelial cells lining blood vessel walls (Fig. 6). Taken together, the data indicate that the AR phosphorylated on specific serine residues is detectable in cells of the primate ovary.

As a control for staining specificity of the antiphosphoserines 81, 308, and 650 antibodies, positive staining was efficiently competed with the respective phosphoserine peptide (Fig. 7 panels a-f). AR-positive immunostaining using the $\mathrm{N} 20$ antibody was not significantly impaired in the presence of these peptides (Fig. 7 panel $\mathrm{h}$ and data not shown).

The phosphorylation of the AR on serines 81,308 , and 650 was not significantly altered by manipulating the hormonal environment (Figs 3-5); thus, antagonizing GNRH action or raising testosterone levels cause morphological changes in the primate ovary, but had little impact on the phosphorylation status of the AR. Overall AR phosphorylation on serines 81, 308, and 650 was detected in several cell types of the primate ovary, most notably the granulosa cells of developing follicles and in regions of the OSE, together with theca and stromal cells and a proportion of endothelial cells lining blood vessels.

\section{Discussion}

The marmoset model has proved useful in understanding primate ovarian biology and has the advantage that extensive studies have been carried out on manipulating the hormone environment in vivo. In this study, we have confirmed and extended previous work reporting AR expression in the primate ovary. Nuclear immunopositive staining of total AR was observed strongly in the granulosa cells, but also in the OSE, theca cell layer and stroma cells, and in a proportion of endothelial cells lining blood vessels. These findings are in good agreement with earlier work describing the similar expression patterns of the AR mRNA and/or protein in the rhesus monkey, marmoset, and human ovary (Chadha et al. 1994, Hillier et al. 1997, Weil et al. 1998, Saunders et al. 2000). Significantly, we show that phosphorylated forms of the AR are present primarily in granulosa cells, but also in other cell types including the OSE and endothelial cells.

In addition to their presence in the hormoneproducing cells of the follicle, the presence of AR and its phosphorylated forms in the OSE and a subset of ovarian endothelial cells indicate that ovarian blood vessels and OSE may be a target for androgen action. AR has been localized in endothelial cells in a number of tissues (Pelletier et al. 2000, Gonzales et al. 2007), but its 
A

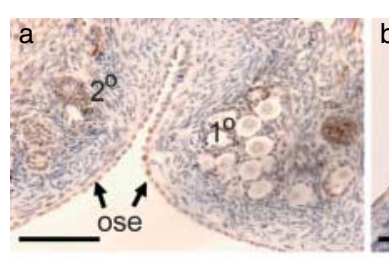

b

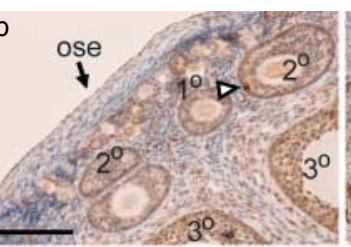

pSer308

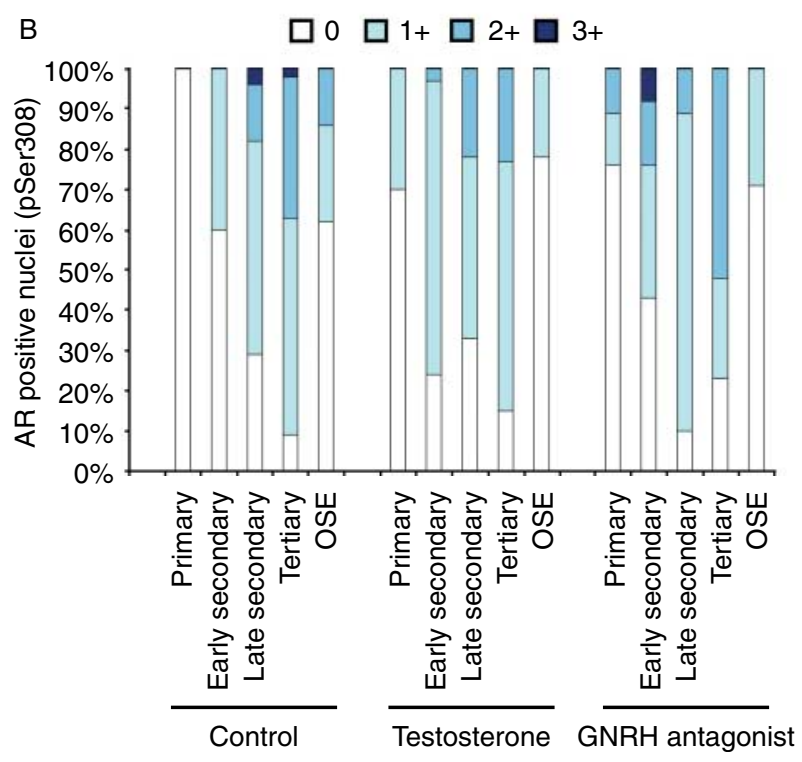

GNRH antagonist

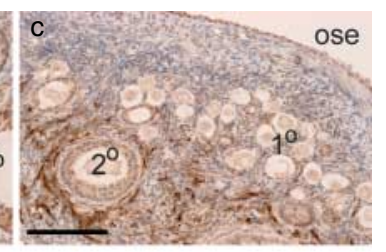

Figure 4 Detection of AR phosphorylated on serine 308. (A) Immunohistochemistry staining for AR using an antibody against phosphoserine 308 (pSer308). Panel a, control animal (day 5); panel $b$, after treatment with testosterone propionate; and panel c, after treatment with GNRH antagonist. Panels a-c represent $\times 20$ magnification; size bar $=100 \mu \mathrm{m} .1^{\circ}, 2^{\circ}$, and $3^{\circ}$ examples of primary, secondary, and tertiary follicles are shown; OSE, ovarian surface epithelium. Open arrow head represents an example of a strongly staining cell. (B) Scoring for the relative strength of staining for total $A R$ in control animals (day 5); after treatment with GNRH antagonist on day 0; and after treatment with testosterone propionate on day 0 . Ovaries from four animals were analyzed for each condition, and scoring was done as detailed in Materials and methods. Briefly, only primary/ transitional and secondary follicles with a clearly visible oocyte were scored as follows: 0 , no detectable staining; $1+, 2+$, and $3+$, weak, moderate, and strong staining respectively. The percentage of granulosa cells at each intensity for primary, secondary, and tertiary follicles has been plotted together with the percentage of OSE. role in influencing vascular development and function is unclear. Several other factors have been shown to have major actions on these cells (Fraser \& Duncan 2009), and it is likely that these potential sites of action are of much less significance than the role of androgen on the granulosa cells. Several studies have observed the expression of the AR in the OSE and the epithelial cells of inclusions cysts (see Saunders et al. 2000, Edmondson et al. 2002). Also androgen stimulation of primary cultures of human OSE cells increased cell proliferation (Edmondson et al. 2002), suggesting that the OSE is an androgen target.

In cell culture systems, phosphorylation of serines 81, 308 , and 650 has been shown to be induced by androgen treatment (see Gioeli et al. 2002). Furthermore, a number of kinases capable of phosphorylating these residues have been identified in vitro. In the case of phosphorylation of serines 81 and 308, the cell cycle-dependent kinases 1 and 11 have been implicated (Chen et al. 2006, Zong et al. 2007). Phosphorylation of serine 308 has been associated with repression of AR activity by cyclin D3/CDK11 (Zong et al. 2007). Furthermore, targeting the receptor to the cytoplasmic or nuclear compartments resulted in a bias of nuclear phosphorylation of serines 81 and 308 (Kesler et al. 2007), which the authors suggest plays a role in nucleocytoplasmic shuttling. However, earlier studies failed to see a role for serine 81 phosphorylation in transactivation assays (Jenster et al. 1994, Zhou et al. 1995) or nuclear/cytoplasmic distribution (Jenster et al. 1994). Consistent with a lack of effect directly on transactivation, Paschal and co-workers (Black et al. 2004) reported that serine 81 phosphorylation occurs subsequent to receptor-co-regulatory protein interactions. In the absence of an unambiguous role for phosphorylation of the individual serines at positions 81 and 308, it is tempting to speculate that what matters is the net phosphorylation of the receptor rather than modification of individual residues. Alternatively, it is conceivable that the functional consequences of phosphorylating individual serines maybe cell and/or gene specific. Further work will be necessary to distinguish these possibilities.

Serine 650 can be phosphorylated in vitro by protein kinase $A$ and protein kinase $C$ and by members of the MAPK family, including the stress-induced kinases $p 38 \alpha$ and JNK (Gioeli et al. 2002, 2006). Although phosphorylation of this residue is well documented, the functional consequences of this modification remain a subject of debate. Initial studies reported a modest impairment of transactivation when the serine is mutated to alanine (S650A; Zhou et al. 1995), and the functionally similar mutation to glycine (S650G) is associated with mild androgen insensitivity syndrome 
A
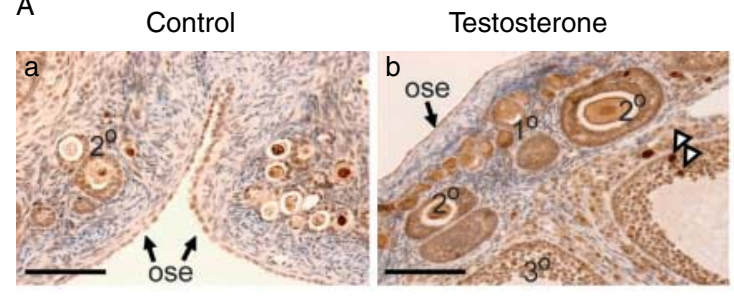

pSer650

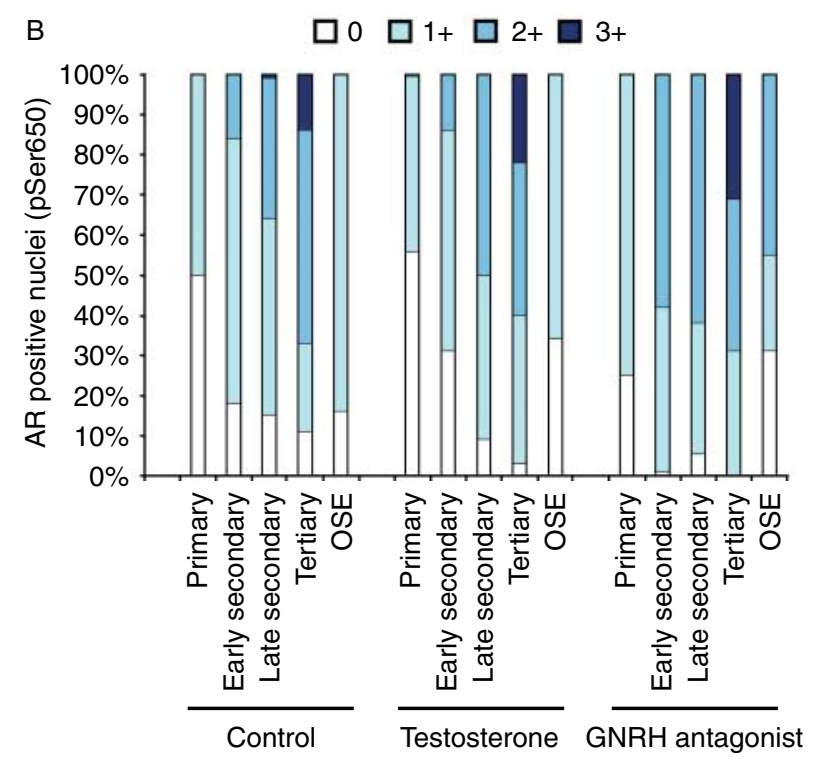

GNRH antagonist

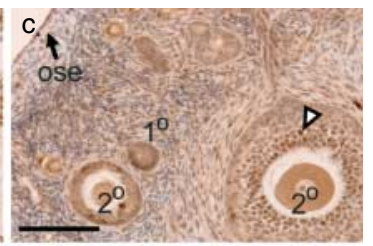

Figure 5 Detection of AR phosphorylated on serine 650. (A) Immunohistochemistry staining for AR using an antibody against phosphoserine 650 (pSer650). Panel a, control animal (day 5); panel b, after treatment with testosterone propionate; and panel c, after treatment with GNRH antagonist. Panels a-c represent $\times 20$ magnification; size bar $=100 \mu \mathrm{m} .1^{\circ}, 2^{\circ}$, and $3^{\circ}$ examples of primary, secondary, and tertiary follicles are shown; OSE, ovarian surface epithelium. Open arrow head represents an example of a strongly staining cell. (B) Scoring for the relative strength of staining for total $A R$ in control animals (day 5); after treatment with GNRH antagonist on day 0; and after treatment with testosterone propionate on day 0 . Ovaries from four animals were analyzed for each condition, and scoring was done as detailed in Materials and methods. Briefly, only primary/ transitional and secondary follicles with a clearly visible oocyte were scored as follows: 0 , no detectable staining; $1+, 2+$, and $3+$, weak, moderate, and strong staining respectively. The percentage of granulosa cell at each intensity for primary, secondary, and tertiary follicles has been plotted together with the percentage of OSE.
(Ferlin et al. 2006) and male infertility (Zuccarello et al. 2008). On the other hand, others have found no major changes in protein-protein interactions or transactivation activity with the same mutation (Wong et al. 2004). More recently, Gioeli et al. (2006) have demonstrated that serine 650 phosphorylation regulates nuclear export, with the non-phosphorylatable S650A mutant receptor retained in the nucleus and a concomitant increase in a target gene expression. Similarly, Chen et al. (2009) reported that serine 650 phosphorylation was a target for protein phosphatase 1 , and it was involved in nuclear export and subsequent receptor turnover. However strikingly, in the present study, immunodetection of phosphoserines 81, 308, and 650 in vivo appeared predominantly nuclear, although some cytoplasmic staining was also observed.

The gonadotropins FSH and LH play critical roles in folliculogenesis, theca and granulosa cell functions, and ovulation, including the LH-stimulated activation of androgen biosynthesis in theca cells (Fauser \& Van Heusden 1997, Hillier 2001, Jamnongjit \& Hammes 2006). The release of these peptide hormones from the pituitary is in turn regulated by GNRH. Treatment of animals with a GNRH antagonist on day 0 of the ovulatory cycle results in inhibition of development of large dominant follicles and suppression of ovarian sex hormone secretion (Taylor et al. 2004). The likely deprivation of the follicles of intra-ovarian androgen might have been expected to result in decreased expression of the $A R$ and impact directly on $A R$ phosphorylation. Conversely, treatment with testosterone propionate throughout the follicular phase might have been expected to increase expression and phosphorylation. An increase in AR in the testosterone propionate ovaries was confirmed; however, our semiquantitative scoring did not reveal substantive changes in any other parameters following these treatments. This indicates that AR phosphorylation in ovarian compartments is not closely regulated by testosterone, at least over the 10-day period of the present study. Interestingly, an increase in receptor mRNA has been observed in the granulosa cells in the rhesus monkey after testosterone treatment and was correlated with cell proliferation (Weil et al. 1998). Although phosphorylation on serines 81,308 , and 650 is refractory to hormone manipulation in vivo, it does not necessarily follow that phosphorylation plays no role in receptor function in the primate ovary, and this is an area of ongoing investigation.

To date, phosphorylation of the AR has been studied almost exclusively in cell culture-based systems with exogenously expressed receptor or in the bone-derived metastatic prostate cancer cell line $\mathrm{LNCaP}$, containing a mutant AR. In the present study, we have uniquely 

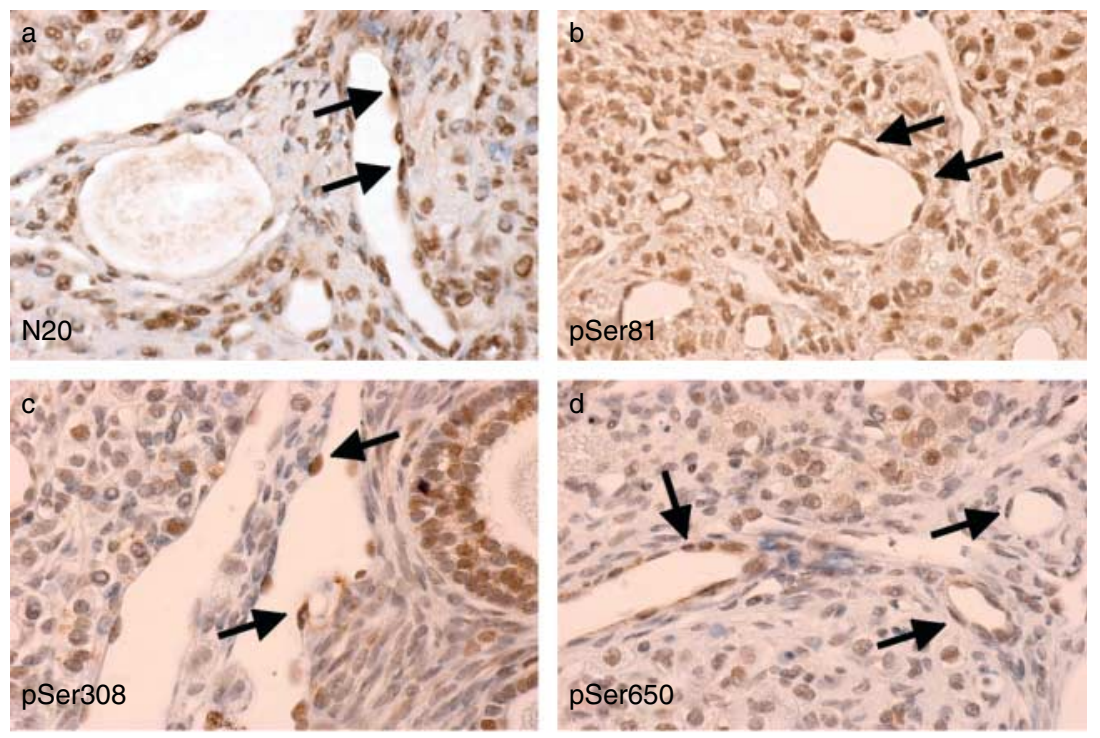

Figure 6 Total AR and phosphorylated forms in endothelial cells. Detection of total AR (N20) and phosphorylated forms (serines 81, 308, and $650)$ in a proportion of endothelial cells $(\rightarrow)$ lining blood vessels. Staining is of an ovary from a control animal. demonstrated in vivo phosphorylation of the AR in a reproductive tissue. These findings complement and expand upon work describing the presence of phosphorylated serine 213 in the developing and adult prostate gland (Taneja et al. 2005) and in clinical samples of prostate cancer (McCall et al. 2008). Taken together with the present study, these data indicate that phosphorylation of the AR has the potential to regulate receptor function in male and female reproductive tissues and in disease.

\section{Materials and Methods \\ Antibodies}

Total AR protein expression was detected using a rabbit polyclonal antibody (N20, sc-816) raised against the receptor N-terminus (Santa Cruz Biotechnology Inc., Santa Cruz, CA, USA). Antibodies recognizing phosphoserines 81 (Millipore Ltd (UK), Watford, UK), 308 (sc26406-R; Santa Cruz Biotechnology Inc.), and 650 (ab47563; Abcam, Cambridge, UK) were all rabbit polyclonals raised against phosphoserinecontaining peptides derived from the human AR sequence.

\section{Animals, treatments and tissue collection}

As the objective was to determine changes in receptor localization during follicular development, control ovaries were examined at two stages of the follicular phase of the ovulatory cycle. To synchronize the timing of events during the cycle, adult female marmosets were injected with $1 \mu \mathrm{g}$ prostaglandin $\mathrm{PGF}_{2 \alpha}$ analog (cloprostenol, Planate; Coopers Animal Health Ltd, Crewe, UK), i.m. on day 13-15 of the luteal phase to induce luteolysis. The day of prostaglandin injection was designated as follicular day 0 . This method of synchronizing follicular recruitment was followed by follicle selection on day 5 and ovulation between day 9 and 11 . Thus, ovaries were studied on day 5 as they contained an abundance of healthy tertiary follicles and on day 10 of the cycle when pre-ovulatory follicles were present. To study the effects of sex hormone ablation on the one hand and hyperstimulation with testosterone on the other hand, marmosets ( $n=4$ per group) were injected with $\mathrm{PGF}_{2 \alpha}$ analog as the controls, but were treated on day 0 with either a GNRH antagonist, Teverelix $\left[\mathrm{N}-\mathrm{Ac}-\mathrm{D}-\mathrm{Nal}{ }^{1}, \mathrm{D}-\mathrm{pCl}-\mathrm{Phe}^{2}, \mathrm{D}-\mathrm{Pal}{ }^{3}, \mathrm{D}-(\mathrm{Hci})^{6}, \mathrm{Lys}(\mathrm{iPr})^{8},{ }^{8} \mathrm{D}-\mathrm{Ala}^{10}{ }^{10}\right]$ GNRH (Europeptides, Argenteuil, France), $12 \mathrm{mg} / \mathrm{kg}$, s.c., to block gonadotropin secretion (Taylor et al. 2004), or testosterone propionate (AMS Biotechnology, Abingdon, UK), $20 \mathrm{mg}$, s.c., in $200 \mu \mathrm{l}$ vegetable oil repeated on days, 1, 3, 5, 7, and 9. On day 10, animals were killed as described previously (Taylor et al. 2004), and ovaries were collected into $4 \%$ neutralbuffered formalin for $24 \mathrm{~h}$ before being transferred into $70 \%$ ethanol, dehydrated, and embedded in paraffin according to standard procedures. Ovaries from control and GNRH antagonist treatments had been stored at room temperature in paraffin blocks having been generated from previously described experiments (Taylor et al. 2004, 2007). Treatment with testosterone propionate was carried out in accordance with the Animals (Scientific Procedures) Act, 1986, and approved by the Local Ethical Review Process Committee. Ovarian sections $(5 \mu \mathrm{m})$ were cut onto SuperFrost slides (BDH, Merck Co., Inc.), and stained with hematoxylin and eosin or subjected to immunohistochemistry as described below.

\section{Marmoset androgen receptor}

The coding sequence of the marmoset AR gene and conceptual translation were determined in two stages. Initially, sequences of human AR exons were used to blast the $C$. jacchus genomesequencing database at the Genome Sequencing Center at Washington University Medical School, St Louis, MO, USA (http://genome.wustl.edu). High scoring segments were employed to download sequencing traces from the National Center for Biotechnology Information Trace Archive, and these were aligned using ClustalW2 (Larkin et al. 2007). Sequences shared between three and six traces were assembled to create contiguous regions of the gene, which were used to confirm 

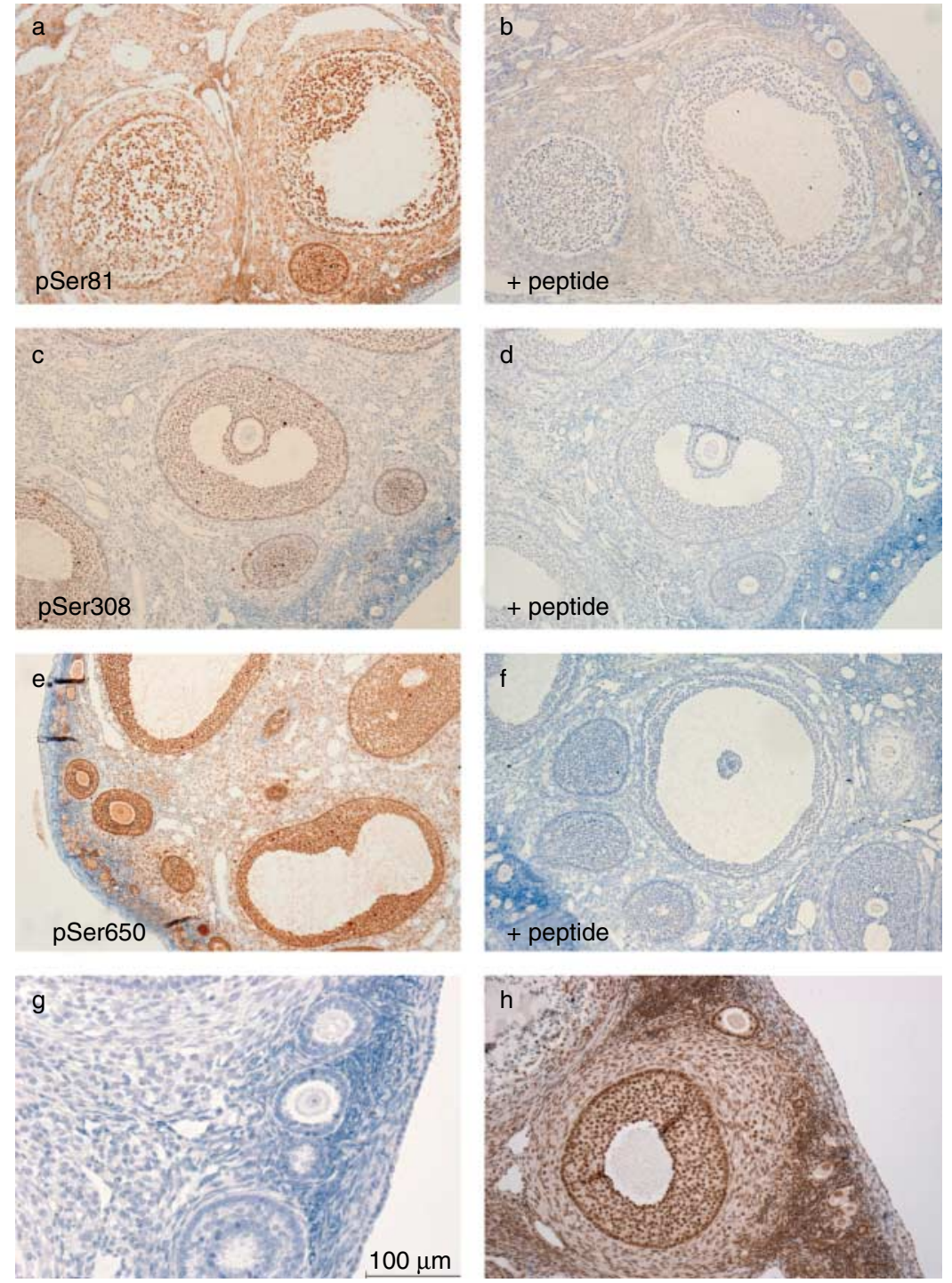

Figure 7 Specificity of phospho-specific antibodies. Panels a, c, and e show staining of follicles for phosphoserines 81,308 , and 650 respectively. Panels $b, d$, and $f$ represent staining in the presence of competing amounts of the cognate phosphopeptide. Panel g represents no primary antibody. Panel h represents staining for AR with $\mathrm{N} 20$ in the presence of an excess of phosphoserine 81 peptide. Magnification $\times 10$. intron/exon splice junctions. The coding sequence was subsequently translated to give a predicted protein primary sequence. Most recently, the coding sequence was confirmed by comparison to the $6 \times$ whole-genome shotgun supercontig 3.2.

\section{Immunohistochemistry}

After dewaxing and rehydration of tissue sections, antigen retrieval was achieved in $50 \mathrm{mM}$ glycine-EDTA buffer $(\mathrm{pH} 8)$ for $5 \mathrm{~min}$ in a pressure cooker. Slides were then blocked with $3 \%$ (v/v) $\mathrm{H}_{2} \mathrm{O}_{2}$ in methanol for $30 \mathrm{~min}$, and washed with water and then with $50 \mathrm{mM}$ Tris- $\mathrm{HCl}(\mathrm{pH} 7.4)$ and $150 \mathrm{mM} \mathrm{NaCl}$ (TBS). Slides were blocked with $20 \%$ normal goat or horse serum and $5 \%$ BSA in TBS for up to $1 \mathrm{~h}$ prior to incubation overnight at $4{ }^{\circ} \mathrm{C}$ with primary antibodies. Antibodies were used at the following dilutions: N20 (1:200, $3 \mathrm{nM})$; pSerine $81(1: 50,0.07 \mu \mathrm{M})$; pSerine 308 (1:100, $0.01 \mu \mathrm{M})$; and pSerine $650(1: 25,0.27 \mu \mathrm{M})$. Slides were then washed twice with TBS, and incubated with goat or horse anti-rabbit secondary antibody with polymerized reporter enzyme staining system (EnVision; Dako
Corporation, Copenhagen, Denmark; or ImmPress, Vector Labs, Peterborough, UK) for up to $1 \mathrm{~h}$ at room temperature. After two wash steps with TBS, DAB substrate was added, and the reaction developed for 2-4 $\mathrm{min}$. Images were captured using a Provis microscope (Olympus Corp., London, UK). All ovaries were subjected to immunohistochemistry in the same run.

Competing peptides containing phosphorylated serine residues were custom synthesized by EZBiolab (Westfield, IN, USA): pSerine 81 QQQQQQQETpSPRQQ; pSerine 308 KSTEDTAEYpSPFKG; and pSerine650 EEGEASSTTpSPTEE. Peptides were added to antibody solutions at concentrations ranging from 0.03 to $2.58 \mathrm{mM}$ prior to tissue incubation.

\section{Analysis of sections}

Stages of follicular development were defined as described previously (Taylor et al. 2004, 2007), i.e. primordial (oocyte surrounded by a few flattened granulosa cells), transitory (oocyte surrounded by flattened granulosa cells and at least one cuboidal granulosa cell), primary (oocyte surrounded by 
a complete layer of cuboidal cells), early secondary (two to four granulosa cell layers, no antrum), late secondary (more than four granulosa cell layers, no antrum), tertiary (follicles containing an antrum), and dominant (large antral follicles, $>2 \mathrm{~mm}$ ). Follicles were classified as healthy if they contained a normal-shaped oocyte surrounded by granulosa cells that were regularly apposed on an intact basement membrane with normal appearance of granulosa cell nuclei without signs of pycnosis. For examination of primordial to late secondary follicles, only those with a visible oocyte containing a nucleus were considered to ensure proper follicular classification. Follicles were classified as atretic when more than $5 \%$ of granulosa cells showed signs of pycnosis and detachment of cells from the basement membrane. The numbers of follicles analyzed were as follows: controls (transitory/primary, $n=262$; early secondary, $n=154$; late secondary, $n=29$; tertiary, $n=200$; dominant, $n=26$; and atretic, $n=19$ ); GNRH antagonist-treated (transitory/primary, $n=287$; early secondary, $n=148$; late secondary, $n=48$; tertiary, $n=142$; dominant, $n=0$; and atretic, $n=21$ ), and testosterone propionate-treated (transitory/primary, $n=274$; early secondary, $n=137$; late secondary, $n=36$; tertiary, $n=103$; dominant, $n=2$; and atretic, $n=39$ ).

Sections were analyzed by two observers blinded to the treatment category. The degree of staining for AR protein was based upon a modified HSCORE. Thus, intensity of staining in granulosa cells and OSE was classed as 1, weak; 2, moderate; 3 , strong. The percentage of granulosa cells and OSE at each intensity was then calculated. Theca and endothelial cells were also examined.

\section{Immunoprecipitation and western blot analysis of the marmoset $A R$}

For IP, a single normal ovary was homogenized using RIPA buffer (1\% Triton X-100, 0.25\% sodium deoxycholate, $50 \mathrm{mM}$ Tris- $\mathrm{HCl}$ (pH 7.4), $150 \mathrm{mM} \mathrm{NaCl}$, and $1 \mathrm{mM}$ EDTA) containing protease inhibitors (Complete Mini protease inhibitor cocktail (Roche) and $1 \mathrm{mM}$ phenylmethylsulfonyl fluoride) and phosphatase inhibitors (2 $\mathrm{mM}$ activated $\mathrm{Na}_{3} \mathrm{VO}_{4} ; 50 \mathrm{mM}$ $\mathrm{NaF}$; $20 \mathrm{mM}$-glycerophosphate disodium; phosphatase inhibitor cocktail containing cantharidin, bromotetramisole, and microcystin-LR (Sigma-Aldrich)). Protease and phosphatase inhibitors were added to the lysis buffer just before homogenization. The AR was immunoprecipitated from an aliquot of $0.5 \mathrm{mg}$ protein $/ \mathrm{ml}$ using $2.5 \mu \mathrm{g}$ of anti-human $\mathrm{AR}$ (C-19, Santa Cruz Biotechnology Inc.) and protein A affinity resin (Sigma-Aldrich). For each IP experiment, appropriate negative controls (rabbit IgG and rabbit serum) were conducted simultaneously. Prior to the incubation with the C-19 antibody, the tissue homogenate was precleared with protein $\mathrm{A}$ resin. The final pellets were washed three times with $\mathrm{Ca}^{2+} / \mathrm{Mg}^{2+} \mathrm{PBS}$. Purified immune complexes associated with AR were mixed with $2 \times$ electrophoresis sample buffer, boiled, and then resolved by SDS-PAGE. These complexes were further analyzed by western blotting using antibodies raised against $A R$ and specific serine phosphorylation sites. Briefly, membranes were blocked with 5\% non-fat dry milk/TBS for $1 \mathrm{~h}$ followed by incubation with primary antibodies diluted in 5\% milk/TBS for $2 \mathrm{~h}$ at room temperature: $\mathrm{N} 20$ (1:100), pSerine81 (1:500), pSerine308 (1:200), and pSerine650 (1:200). The secondary antibodies such as IRDye680conjugated affinity-purified goat anti-mouse IgG or IRDye800CW-conjugated affinity-purified goat anti-rabbit IgG (Li-COR Biosciences, Cambridge, UK) at 1:1000 dilution were incubated for an hour. Fluorescence was analyzed using the Odyssey Infrared Imaging system from LI-COR Biosciences. To verify the specificity of $A R$, phosphoserine antibodies blocking peptides and $\lambda$ protein phosphatase $\left(100 \mathrm{U}\right.$ at $\left.37^{\circ} \mathrm{C}\right)$ treatment were used.

\section{Declaration of interest}

The authors declare that there is no conflict of interest that could be perceived as prejudicing the impartiality of the research reported.

\section{Funding}

This work was supported by funding from the Medical Research Council, UK.

\section{Acknowledgements}

We gratefully acknowledge the technical assistance of Helen Wilson and the Histology Core service for helping to carry out this study. We particularly acknowledge Sheila MacPherson and Mike Millar and Dr Julie Hastings for providing material.

\section{References}

Black BE, Vitto MJ, Gioeli D, Spencer A, Afshar N, Conaway MR, Weber MJ \& Paschal BM 2004 Transient, ligand-dependent arrest of the androgen receptor in subnuclear foci alters phosphorylation and coactivator interactions. Molecular Endocrinology 18 834-850.

Blok LJ, de Ruiter PE \& Brinkmann AO 1998 Forskolin-induced dephosphorylation of the androgen receptor impairs ligand binding. Biochemistry 37 3850-3857.

Callewaert L, Verrijdt G, Haelens A \& Claessens F 2004 Differential effect of small ubiquitin-like modifier (SUMO)-ylation of the androgen receptor in the control of cooperativity on selective versus canonical response elements. Molecular Endocrinology 18 1438-1449.

Chadha S, Pache TD, Huikeshoven JM, Brinkmann AO \& van der Kwast TH 1994 Androgen receptor expression in human ovarian and uterine tissue of long-term androgen-treated transsexual women. Human Pathology 25 1198-1204.

Chaffin CL, Stouffer RL \& Duffy DM 1999 Gonadotropin and steroid regulation of steroid receptor and aryl hydrocarbon receptor messenger ribonucleic acid in macaque granulosa cells during the periovulatory interval. Endocrinology 140 4753-4760.

Chen S, Xu Y, Yuan X, Bubley GJ \& Balk SP 2006 Androgen receptor phosphorylation and stabilization in prostate cancer by cyclin-dependent kinase 1. PNAS 103 15969-15974.

Chen S, Kesler CT, Paschal BM \& Balk SP 2009 Androgen receptor phosphorylation and activity are regulated by an association with protein phosphatase 1. Journal of Biological Chemistry 284 25576-25584.

Edmondson RJ, Monaghan JM \& Davies BR 2002 The human ovarian surface epithelium is an androgen responsive tissue. British Journal of Cancer 86 879-885.

Fauser BC \& Van Heusden AM 1997 Manipulation of human ovarian function: physiological concepts and clinical consequences. Endocrine Reviews 18 71-106. 
Ferlin A, Vinanzi C, Garolla A, Selice R, Zuccarello D, Cazzadore C \& Foresta C 2006 Male infertility and androgen receptor gene mutations: clinical features and identification of seven novel mutations. Clinical Endocrinology 65 606-610.

Fraser HM \& Duncan WC 2009 SRB Reproduction, Fertility and Development Award Lecture 2008. Regulation and manipulation of angiogenesis in the ovary and endometrium. Reproduction, Fertility, and Development 21 377-392.

Fu M, Wang C, Wang J, Zhang X, Sakamaki T, Yeung YG, Chang C, Hopp T, Fuqua SA, Jaffray E et al. 2002 Androgen receptor acetylation governs trans activation and MEKK1-induced apoptosis without affecting in vitro sumoylation and trans-repression function. Molecular and Cellular Biology 22 3373-3388.

Gaughan L, Logan IR, Cook S, Neal DE \& Robson CN 2002 Tip60 and histone deacetylase 1 regulate androgen receptor activity through changes to the acetylation status of the receptor. Journal of Biological Chemistry 277 25904-25913.

Gelmann EP 2002 Molecular biology of the androgen receptor. Journal of Clinical Oncology 20 3001-3015.

Gilchrist RB, Wicherek M, Heistermann M, Nayudu PL \& Hodges JK 2001 Changes in follicle-stimulating hormone and follicle populations during the ovarian cycle of the common marmoset. Biology of Reproduction $\mathbf{6 4}$ 127-135.

Gioeli D, Ficarro SB, Kwiek JJ, Aaronson D, Hancock M, Catling AD, White FM, Christian RE, Settlage RE, Shabanowitz J et al. 2002 Androgen receptor phosphorylation. Regulation and identification of the phosphorylation sites. Journal of Biological Chemistry 277 29304-29314.

Gioeli D, Black BE, Gordon V, Spencer A, Kesler CT, Eblen ST, Paschal BM \& Weber MJ 2006 Stress kinase signaling regulates androgen receptor phosphorylation, transcription, and localization. Molecular Endocrinology 20 503-515.

Gonzales RJ, Ansar S, Duckles SP \& Krause DN 2007 Androgenic/ estrogenic balance in the male rat cerebral circulation: metabolic enzymes and sex steroid receptors. Journal of Cerebral Blood Flow and Metabolism 27 1841-1852.

Hickey TE, Marrocco DL, Amato F, Ritter LJ, Norman RJ, Gilchrist RB \& Armstrong DT 2005 Androgens augment the mitogenic effects of oocyte-secreted factors and growth differentiation factor 9 on porcine granulosa cells. Biology of Reproduction 73 825-832.

Hild-Petito S \& Fazleabas AT 1997 Expression of steroid receptors and steroidogenic enzymes in the baboon (Papio anubis) corpus luteum during the menstrual cycle and early pregnancy. Journal of Clinical Endocrinology and Metabolism 82 955-962.

Hillier SG 2001 Gonadotropic control of ovarian follicular growth and development. Molecular and Cellular Endocrinology 179 39-46.

Hillier SG, Tetsuka M \& Fraser HM 1997 Location and developmental regulation of androgen receptor in primate ovary. Human Reproduction 12 107-111.

Horie K, Takakura K, Imai K, Liao S \& Mori T 1992 Immunohistochemical localization of androgen receptor in the human endometrium, decidua, placenta and pathological conditions of the endometrium. Human Reproduction 7 1461-1466.

Hu YC, Wang PH, Yeh S, Wang RS, Xie C, Xu Q, Zhou X, Chao HT, Tsai MY \& Chang C 2004 Subfertility and defective folliculogenesis in female mice lacking androgen receptor. PNAS 101 11209-11214.

Jamnongjit M \& Hammes SR 2006 Ovarian steroids: the good, the bad, and the signals that raise them. Cell Cycle 5 1178-1183.

Jenster G, de Ruiter PE, van der Korput HA, Kuiper GG, Trapman J \& Brinkmann AO 1994 Changes in the abundance of androgen receptor isotypes: effects of ligand treatment, glutamine-stretch variation, and mutation of putative phosphorylation sites. Biochemistry 33 14064-14072.

Juengel JL, Heath DA, Quirke LD \& McNatty KP 2006 Oestrogen receptor alpha and beta, androgen receptor and progesterone receptor mRNA and protein localisation within the developing ovary and in small growing follicles of sheep. Reproduction 131 81-92.

Kesler CT, Gioeli D, Conaway MR, Weber MJ \& Paschal BM 2007 Subcellular localization modulates activation function 1 domain phosphorylation in the androgen receptor. Molecular Endocrinology 21 2071-2084.
Kimura S, Matsumoto T, Matsuyama R, Shiina H, Sato T, Takeyama K \& Kato S 2007 Androgen receptor function in folliculogenesis and its clinical implication in premature ovarian failure. Trends in Endocrinology and Metabolism 18 183-189.

van Laar JH, Berrevoets CA, Trapman J, Zegers ND \& Brinkmann AO 1991 Hormone-dependent androgen receptor phosphorylation is accompanied by receptor transformation in human lymph node carcinoma of the prostate cells. Journal of Biological Chemistry $\mathbf{2 6 6}$ 3734-3738.

Larkin MA, Blackshields G, Brown NP, Chenna R, McGettigan PA, McWilliam H, Valentin F, Wallace IM, Wilm A, Lopez R et al. 2007 Clustal W and Clustal X version 2.0. Bioinformatics 23 2947-2948.

Lenie S \& Smitz J 2009 Functional AR signaling is evident in an in vitro mouse follicle culture bioassay that encompasses most stages of folliculogenesis. Biology of Reproduction 80 685-695.

Lin HK, Yeh S, Kang HY \& Chang C 2001 Akt suppresses androgen-induced apoptosis by phosphorylating and inhibiting androgen receptor. PNAS $\mathbf{9 8}$ 7200-7205.

Lin HK, Wang L, Hu YC, Altuwaijri S \& Chang C 2002 Phosphorylationdependent ubiquitylation and degradation of androgen receptor by Akt require Mdm2 E3 ligase. EMBO Journal 21 4037-4048.

Mahajan NP, Liu Y, Majumder S, Warren MR, Parker CE, Mohler IL, Earp HS \& Whang YE 2007 Activated Cdc42-associated kinase Ack1 promotes prostate cancer progression via androgen receptor tyrosine phosphorylation. PNAS 104 8438-8443.

McCall P, Gemmell LK, Mukherjee R, Bartlett JM \& Edwards J 2008 Phosphorylation of the androgen receptor is associated with reduced survival in hormone-refractory prostate cancer patients. British Journal of Cancer 98 1094-1101.

McEwan IJ 2004 Molecular mechanisms of androgen receptor-mediated gene regulation: structure-function analysis of the AF-1 domain. Endocrine-Related Cancer 11 281-293.

Pelletier G, Labrie C \& Labrie F 2000 Localization of oestrogen receptor alpha, oestrogen receptor beta and androgen receptors in the rat reproductive organs. Journal of Endocrinology 165 359-370.

Ponguta LA, Gregory CW, French FS \& Wilson EM 2008 Site-specific androgen receptor serine phosphorylation linked to epidermal growth factor-dependent growth of castration-recurrent prostate cancer. Journal of Biological Chemistry 283 20989-21001.

Poukka H, Karvonen U, Janne OA \& Palvimo JJ 2000 Covalent modification of the androgen receptor by small ubiquitin-like modifier 1 (SUMO-1). PNAS 97 14145-14150.

Rice S, Ojha K, Whitehead S \& Mason H 2007 Stage-specific expression of androgen receptor, follicle-stimulating hormone receptor, and anti-Mullerian hormone type II receptor in single, isolated, human preantral follicles: relevance to polycystic ovaries. Journal of Clinical Endocrinology and Metabolism 92 1034-1040.

Rigas AC, Ozanne DM, Neal DE \& Robson CN 2003 The scaffolding protein RACK1 interacts with androgen receptor and promotes cross-talk through a protein kinase $\mathrm{C}$ signaling pathway. Journal of Biological Chemistry 278 46087-46093.

Saunders PT, Millar MR, Williams K, Macpherson S, Harkiss D, Anderson RA, Orr B, Groome NP, Scobie G \& Fraser HM 2000 Differential expression of estrogen receptor-alpha and -beta and androgen receptor in the ovaries of marmosets and humans. Biology of Reproduction 63 1098-1105.

Shiina H, Matsumoto T, Sato T, Igarashi K, Miyamoto J, Takemasa S, Sakari M, Takada I, Nakamura T, Metzger D et al. 2006 Premature ovarian failure in androgen receptor-deficient mice. PNAS 103 224-229.

Taneja SS, Ha S, Swenson NK, Huang HY, Lee P, Melamed J, Shapiro E, Garabedian MJ \& Logan SK 2005 Cell-specific regulation of androgen receptor phosphorylation in vivo. Journal of Biological Chemistry $\mathbf{2 8 0}$ 40916-40924.

Taylor PD, Hillier SG \& Fraser HM 2004 Effects of GnRH antagonist treatment on follicular development and angiogenesis in the primate ovary. Journal of Endocrinology 183 1-17.

Taylor PD, Wilson H, Hillier SG, Wiegand SJ \& Fraser HM 2007 Effects of inhibition of vascular endothelial growth factor at time of selection on follicular angiogenesis, expansion, development and atresia in the marmoset. Molecular Human Reproduction 13 729-736. 
Tetsuka M \& Hillier SG 1996 Androgen receptor gene expression in rat granulosa cells: the role of follicle-stimulating hormone and steroid hormones. Endocrinology 137 4392-4397.

Tetsuka M, Whitelaw PF, Bremner WJ, Millar MR, Smyth CD \& Hillier SG 1995 Developmental regulation of androgen receptor in rat ovary. Journal of Endocrinology 145 535-543.

Thomas FH, Telfer EE \& Fraser HM 2007 Expression of anti-Mullerian hormone protein during early follicular development in the primate ovary in vivo is influenced by suppression of gonadotropin secretion and inhibition of vascular endothelial growth factor. Endocrinology 148 2273-2281.

Vendola K, Zhou J, Wang J \& Bondy CA 1999 Androgens promote insulin-like growth factor-I and insulin-like growth factor-I receptor gene expression in the primate ovary. Human Reproduction 14 2328-2332.

Walters KA, Allan CM, Jimenez M, Lim PR, Davey RA, Zajac JD, Illingworth P \& Handelsman DJ 2007 Female mice haploinsufficient for an inactivated androgen receptor (AR) exhibit age-dependent defects that resemble the AR null phenotype of dysfunctional late follicle development, ovulation, and fertility. Endocrinology $\mathbf{1 4 8}$ 3674-3684.

Weil SJ, Vendola K, Zhou J, Adesanya OO, Wang J, Okafor J \& Bondy CA 1998 Androgen receptor gene expression in the primate ovary: cellular localization, regulation, and functional correlations. Journal of Clinical Endocrinology and Metabolism 83 2479-2485.

Weil S, Vendola K, Zhou J \& Bondy CA 1999 Androgen and folliclestimulating hormone interactions in primate ovarian follicle development. Journal of Clinical Endocrinology and Metabolism 84 2951-2956.

Wong HY, Burghoorn JA, Van Leeuwen M, De Ruiter PE, Schippers E, Blok LJ, Li KW, Dekker HL, De Jong L, Trapman J et al. 2004 Phosphorylation of androgen receptor isoforms. Biochemical Journal 383 267-276.
Yang CS, Vitto MJ, Busby SA, Garcia BA, Kesler CT, Gioeli D, Shabanowitz J, Hunt DF, Rundell K, Brautigan DL et al. 2005 Simian virus 40 small $t$ antigen mediates conformation-dependent transfer of protein phosphatase $2 \mathrm{~A}$ onto the androgen receptor. Molecular and Cellular Biology 25 1298-1308.

Yang CS, Xin HW, Kelley JB, Spencer A, Brautigan DL \& Paschal BM 2007 Ligand binding to the androgen receptor induces conformational changes that regulate phosphatase interactions. Molecular and Cellular Biology 27 3390-3404.

Yeh S, Tsai MY, Xu Q, Mu XM, Lardy H, Huang KE, Lin H, Yeh SD, Altuwaijri S, Zhou X et al. 2002 Generation and characterization of androgen receptor knockout (ARKO) mice: an in vivo model for the study of androgen functions in selective tissues. PNAS 99 13498-13503.

Zhou ZX, Kemppainen JA \& Wilson EM 1995 Identification of three prolinedirected phosphorylation sites in the human androgen receptor. Molecular Endocrinology 9 605-615.

Zhu Z, Becklin RR, Desiderio DM \& Dalton JT 2001 Identification of a novel phosphorylation site in human androgen receptor by mass spectrometry. Biochemical and Biophysical Research Communications 284 836-844.

Zong H, Chi Y, Wang Y, Yang Y, Zhang L, Chen H, Jiang J, Li Z, Hong Y, Wang H et al. 2007 Cyclin D3/CDK11p58 complex is involved in the repression of androgen receptor. Molecular and Cellular Biology 27 7125-7142.

Zuccarello D, Ferlin A, Vinanzi C, Prana E, Garolla A, Callewaert L, Claessens F, Brinkmann AO \& Foresta C 2008 Detailed functional studies on androgen receptor mild mutations demonstrate their association with male infertility. Clinical Endocrinology 68 580-588.

Received 15 March 2010

First decision 15 April 2010

Accepted 20 April 2010 